Fanum

Sociológico

\section{Forum Sociológico}

Série II

27 | 2015

Mobilidade científica \& imigração qualificada

\title{
Cooperação Sul-Sul, uma via alternativa ? Um caso exploratório entre Brasil e Argentina
}

\section{Thais França e Beatriz Padilla}

\section{(2) OpenEdition \\ 1 Journals}

\section{Edição electrónica}

URL: https://journals.openedition.org/sociologico/1336

DOI: 10.4000/sociologico.1336

ISSN: 2182-7427

\section{Editora}

CICS.NOVA - Centro Interdisciplinar de Ciências Sociais da Universidade Nova de Lisboa

\section{Edição impressa}

Data de publição: 21 dezembro 2015

Paginação: 61-71

ISSN: 0872-8380

\section{Refêrencia eletrónica}

Thais França e Beatriz Padilla, «Cooperação Sul-Sul, uma via alternativa ? Um caso exploratório entre Brasil e Argentina», Forum Sociológico [Online], 27 | 2015, posto online no dia 31 maio 2016, consultado o 31 março 2022. URL: http://journals.openedition.org/sociologico/1336 ; DOI: https:// doi.org/10.4000/sociologico.1336 


\title{
COOPERAÇÃO SUL-SUL, UMA VIA ALTERNATIVA? UM CASO EXPLORATÓRIO ENTRE BRASIL E ARGENTINA
}

\author{
Thais França \\ Universidade do Minho, Centro Interdisciplinar de Ciências Sociais, CICS.NOVA (Polo UMinho)
}

Beatriz Padilla

Instituto Universitário de Lisboa (ISCTE-IUL), Centro de Investigação e Estudos de Sociologia (CIES-IUL) \& Universidade Nova de Lisboa, Centro Interdisciplinar de Ciências Sociais (CICS.NOVA)

\begin{abstract}
Resumo
A cooperação académica e científica internacional vem tornando-se cada vez mais relevante, não apenas desde uma perspetiva do desenvolvimento da ciência, mas também do crescimento económico dos países envolvidos. Apesar dos inúmeros benefícios que aporta - transferência de tecnologia, internacionalização das instituições, circulação de cientistas - por conta das assimetrias e hierarquias geopolíticas e económicas, essas cooperações podem não beneficiar de forma igual todos os países envolvidos. Dentro desta lógica, as cooperações Sul-Sul (CSS) aparecem como uma alternativa inovadora para o desenvolvimento da ciência entre os países do Sul. A partir duma análise documental de alguns acordos celebrados entre agências de fomento à pesquisa, brasileiras e argentinas, especificamente CAPES/CNPq no caso brasileiro e CONICET no caso argentino, este trabalho tem como objetivo discutir como a relação de cooperação científico-académica entre os dois países se tem desenvolvido ao longo dos anos, indagando se tal relação pode ser enquadrada dentro de uma lógica de cooperação Sul-Sul.
\end{abstract}

Palavras-chave: cooperação Sul-Sul, acordos bilaterais, Brasil-Argentina

\begin{abstract}
In the last few decades, international scientific cooperation has become increasingly important, not only from the perspective of the development of science, but also from an economic perspective. Despite the numerous advantages resulting from these cooperations: technology transfer, institutions internationalisation and scientist circulation, other results suggest the uneven geopolitical and economic hierarchies and asymmetries among the countries involved, in which not all equally benefit. The South-South cooperation (SSC) therefore appears as an innovative alternative to South countries science development. Based on a documental analysis of some agreements between the Brazilian and Argentinian national science funding agencies, more specifically CNPq/CAPES in the case of Brazil and CONICET in Argentina, this papers aims to discuss how the academic and scientific cooperation between the two countries has been developing over the years and if it can be considered a sort of SSC.
\end{abstract}

Keywords: South-South cooperation, bilateral agreements, Brazil-Argentina

\section{Cooperação académica científica}

A cooperação científica internacional é uma prática bastante antiga e comum entre universidades e centros de pesquisa de distintos países. Tanto no império árabe islâmico como na China antiga e na Europa medieval a prática de cooperação entre cientistas de diferentes regiões já existia (Dedjier, 1971;
Kim, 2009). Todavia, é inegável, que este fenómeno assumiu novas características e fortaleceu-se mais rapidamente nas últimas décadas como consequência da intensificação dos processos de globalização em curso. Recentemente, a União Europeia no seu relatório de avaliação do 70 Programa Quadro (Remotti, Damvakeraki, Ploder, \& Sterner, 2014) reconhece que a natureza do desenvolvimento das 
ciências e tecnologias é de caráter internacional e o programa Quadro de Ciência, Tecnologia e Inovação do MERCOSUL para 2015-2019 defende que a construção de um espaço de Ciência, Tecnologia e Inovação entre países favorece a consolidação do desenvolvimento científico e tecnológico de toda a região (RECyT, 2015). O crescimento do número de encontros científicos internacionais e de publicações em coautorias internacionais podem ser citados como outro exemplo que corrobora esta afirmação (Vanz \& Stumpf, 2010).

Apesar da relevância que a cooperação científica internacional sempre assumiu, foi apenas recentemente que admitiu o status de objeto e produto de políticas governamentais (Velho, 2000). Nas últimas décadas, a centralidade da chamada "internacionalização da ciência", que na prática se refere mais a internacionalização das universidades e dos centros de investigação do que da ciência propriamente dita, tem contribuído para uma valorização dos processos de cooperação internacional. O termo "internacionalização da ciência" popularizou-se nos anos 1980s com o avanço da lógica neoliberalista nas universidades e centros de investigação e no presente ocupa um lugar central nos diferentes sistemas de rankings das instituições. Por exemplo, entre os indicadores que medem a internacionalização, alguns dos principais parâmetros são: as colaborações de investigação, o grau de internacionalização do corpo académico e estudantil, os apoios existentes aos estudantes internacionais, a percentagem de estudantes provenientes do estrangeiro e que se dirigem ao estrangeiro, e diversidade internacional dos estudantes. Neste sentido, percebe-se porque ganha relevância a cooperação científica internacional.

Os fatores que justificam a popularização das práticas de cooperação científica podem ser categorizados como sociais, económicos e políticos: os baixos custos de deslocação internacional, o aperfeiçoamento de novas tecnologias de informação e comunicação (TIC), a criação de blocos económicos (União Europeia, Mercosul, NAFTA, BRIC), a transnacionalização das empresas, as novas regras de financiamentos para alguns setores de pesquisa que exigem parcerias internacionais, o alto custo de equipamentos ultra especializados (telescópios ou aceleradores de partículas, por exemplo), disseminação de grandes projetos cujas questões ultrapassam fronteiras nacionais (genoma humano, camada de ozono, aquecimento global, pobreza global, doenças infeciosas, abastecimento de água e comida) (Remotti et al., 2014) e a entrada de grandes empresas privadas de tecnologia no mercado da ciência (Corder, Costa, Gomes, \& Velho, 2002). E os benefícios trazidos pela cooperação internacional são inúmeros, dentre eles elenca-se: a otimização nos gastos e recursos, aproveitamento das competências de cada grupo, maior aprofundamento e especialização das pesquisas, divulgação mais rápida e eficaz dos resultados obtidos, aumento no número de publicações, interdisciplinaridade, transferência e circulação de conhecimentos e práticas de investigação, fortalecimento de redes de investigação com parceiros estratégicos, acesso à pesquisas globais, qualificação dos/as investigadores/as envolvidos/ /as, possibilidade de abertura de novas linhas de investigação, benefícios dos estudos comparados, dentre outros.

Em virtude do avanço das TIC's, que permitem a interação à distância de distintos grupos de cientistas, as deslocações físicas, ainda que necessárias, não são mais obrigatórias, ou podem ser encurtadas na dimensão temporal. Desta forma, abre-se espaço para que a colaboração científica tenha lugar além das fronteiras geográficas, possibilitando grupos, que anteriormente, devido às distâncias, jamais poderiam estar em contato, conhecerem os seus trabalhos e desenvolverem pesquisas em parceria. Em simultâneo ao desenvolvimento das TIC's, o baixo custo dos voos internacionais fez com que, apesar da facilidade e do pragmatismo dos novos canais de comunicação virtuais, os encontros reais entre cientistas e investigadores/as de diferentes centros se tenham tornado ainda mais viáveis.

Todavia, é preciso ter claro que o fato de que nos dias de hoje as colaborações internacionais sejam mais comuns não implica que elas se configurem horizontalmente e menos assimétricas entre as áreas de conhecimento e que a todos os centros envolvidos em um projeto de cooperação internacional seja dado o mesmo protagonismo.

A partir deste enquadramento, um dos pontos que merece ser destacado consiste nas hierarquias entre as áreas do conhecimento. Via de regra, as ciências puras e exatas aparecem como as áreas mais subsidiadas, posto que seus projetos estão mais relacionados com o desenvolvimento de tecnologias, cada vez mais importantes no setor industrial e empresarial e nas dinâmica globais de poder político e económico. Já no caso das ciências humanas e sociais, normalmente, os seus objetos de investigação envolvem, de forma intensa, questões culturais, políticas e ideológicas, diretamente ligadas às especificidades dos contextos sócioeconómicos locais, que por vezes vão de encontro aos objetivos das entidades financiadoras, públicas ou privadas ou de alguns dos países envolvidos. Neste sentido, ideológica ou politicamente, pode ser menos atrativo financiar projetos de investigações sobre fenómenos sociais.

Outro aspeto elementar a ser levado em consideração nas cooperações científicas internacionais é o papel do Estado, uma vez que ele continua a ser fundamental como provedor de apoio institucional, político e financeiro (Domingues \& Costa, 2013). Enquanto no Norte Global, há uma cultura mais 
consolidada de investimentos dos Estados em ciência, tecnologia e investigação (sendo preciso ressaltar que nas últimas décadas com o avanço do neoliberalismo na ciência e na academia, algumas áreas têm visto os seus investimentos serem reduzidos de forma drástica) no caso do Sul Global a realidade não é a mesma. Via de regra, os países do Sul têm menos condições económicas e, em alguns casos, menos interesse político em financiar projetos de cooperação internacional, ficando as instituições científicas e académicas destes países reféns das ofertas que lhes são feitas a partir do Norte Global, ou sendo obrigadas a realizar as suas investigações sem recursos financeiros. Esses diferentes posicionamentos dos Estados em relação aos investimentos nas áreas científicas contribuem para que o desenvolvimento da cooperação internacional não se dê da mesma maneira em todas as regiões do mundo, reforçando desigualdades políticas e económicas.

Essas assimetrias geopolíticas continuam a reproduzir hierarquias epistémicas, onde alguns países se posicionam como centros produtores de conhecimento e outros, receptores (Mignolo, 2003b). Neste sentido, alguns países são mais procurados do que outros para estabelecerem relações de cooperação e colaboração científica internacional. Comumente, por conta da capacidade superior de financiamento, melhores condições científicas em termos de acesso a materiais e bibliografias, facilidade de publicações internacionais e maior oferta de grupos de excelência os países do Norte são mais procurados do que os países do Sul para a negociação de projetos de colaboração científica. Portanto, da forma como os programas de cooperação internacional forem estruturados, desigualdades e hierarquias económicas e epistémicas continuarão a ser reproduzidas e reforçadas.

De acordo com as análises Corder et. al. (2002), instituições e investigadores/as privilegiam estabelecer relações de cooperação com grupos que promovem uma melhor inserção científica no cenário internacional e que consigam maiores financiamentos ao invés de compromissos com as relações regionais, por exemplo. Ou seja, via de regra, os países do Sul optam por trabalhar com países do Norte em vez de estabelecer cooperações com outros países do Sul. Contudo, nesta lógica de cooperação Norte-Sul, raros são os casos em que os países do Sul são escolhidos para serem líderes de projetos ou apenas são considerados em pé de igualdade com os países do Norte. Em geral, esses países assumem o papel de coordenadores dos projetos, subordinando aqueles às suas regras e definições teóricas e económicas, perpetuando as relações desiguais e hierárquicas entre Norte e Sul.

Embora seja preciso reconhecer que, não é invulgar um projeto de cooperação científica Norte-Sul resultar numa aproximação entre os centros de países do Sul envolvidos, como foi o caso do Programa ALFA e ALBAN (Programa de Bolsas de Alto Nível da União Europeia para a América Latina) coordenados pela União Europeia de onde resultaram parcerias significativas entre alguns países do Sul. Contudo, apesar de possibilitar estes laços, normalmente, as cooperações internacionais possuem uma agenda a ser cumprida que é voltada principalmente para os interesses dos financiadores, neste caso os países do Norte (Velho, 2000). Isto faz com que os países do Sul assumam o papel de produtores de conhecimento para o Norte, reproduzindo a lógica de subordinação do Sul em relação ao Norte e não privilegiando os seus temas e problemas. Segundo Marí et. al. (2001) desta dinâmica de dependência dos países do Sul em relação à agenda de investigação dos países do Norte resulta uma ciência periférica que se organiza seguindo as pautas das ciências centrais.

Outro fator que ao mesmo tempo que é causa é também resultado, da reprodução das cooperações científicas internacionais em sentido Norte-Sul é a prática comum de investigadores/as do Sul serem treinados/as por investigadores/as do Norte nos seus mestrados, doutoramentos ou pós-doutoramentos. Sabe-se que os vínculos estabelecidos nesta relação costumam ser de grande importância para cooperações e projetos futuros. Neste sentido, o fluxo Sul-Norte de investigadores/as resultante dos projetos de cooperação científica, acabam por fortalecer a dependência do Sul-Norte.

Mignolo (2003a, 2010) analisa esta relação de dependência epistémica e científica entre os países do Sul em relação aos países do Norte a partir de uma leitura descolonial. Para o autor, as origens dos centros de produção de conhecimento do Sul estão inseridas em raízes Europeias que remontam o colonialismo e que numa escala global continuam a serem reproduzidas até aos dias atuais sob os valores do neoliberalismo. Por exemplo, a criação de universidades a partir do século XVI na República Dominicana e no Peru, e posteriormente no século XVII na Argentina, no Chile e no Uruguai está diretamente ligada às práticas de colonização do poder e do saber e consequentemente à legitimação das epistemologias eurocêntricas (Mignolo, 2003a: 100). De acordo com esta perspectiva, ao contrário das ideias que foram naturalizadas de que a produção do conhecimento não possui uma localização geopolítica específica é impossível desagregar essa prática das configurações geopolíticas que classificam hierarquicamente e racialmente as regiões (Mignolo, 2010).

Apesar da forte tendência de hierarquização derivada de assimetrias históricas de poder, políticas e económicas existente nas dinâmicas de cooperação internacional, é fundamental reconhecer que desde os anos 1970 as Cooperações entre países do Sul 
(CSS) têm crescido significativamente, embora ainda figurem como um número bastante reduzido quando comparadas às cooperações Norte-Sul.

A partir de uma leitura global, tal qual aconteceu anteriormente na União Europeia, alguns processos de regionalização e integração, entre os quais se destaca o Mercosul, têm dado relevância à CSS, promovendo o intercâmbio no âmbito de ciência e tecnologia. Ainda com altos e baixos, neste início de século em que alguns países do Sul, como é o caso do Brasil, ganharam maior visibilidade internacional despontando como uma das potências emergentes entre os denominados BRICs (Brasil, Rússia, Índia, China), a CSS e a cooperação triangular mostram-se como uma alternativa viável para o desenvolvimento e crescimento dos países do Sul que não deve ser menosprezada, dado que o mundo "se caracterizará por um maior dinamismo das economias emergentes em comparação com as desenvolvidas" (CEPAL, 2010: 4). A Secretaria Geral Iberoamericana (SEGIB), no seu segundo relatório sobre CSS, constatou que em 2007 houve um total de 1480 ações de cooperação horizontal bilateral entre 19 países ibero-americanos de rendimento médio. Os países com maior destaque foram Cuba, México, Argentina, Chile, Venezuela, Brasil e Colômbia (SEGIB, 2008). Igualmente, a relevância regional que esta dinâmica tem vindo a ganhar nos últimos anos pode ser ilustrada na forma como alguns países da América Latina têm vindo a trabalhar de forma colaborativa na elaboração de indicadores de CSS (Xalma, 2013).

Uma maior concertação entre esses países, mostra-se como uma possibilidade para o reposicionamento do Sul com relação aos países do Norte. Segundo Xalma (2012) a Cooperação Sul-Sul contribui para o desenvolvimento e melhoria das potencialidades entre os países parceiros, numa relação mais horizontal, onde os envolvidos beneficiam entre si de forma mais igualitária do que numa relação Norte-Sul uma vez que se dá entre países com níveis de desenvolvimento semelhantes, ainda que ocorra dentro de uma lógica capitalista neoliberal. Ainda este tipo de cooperação implicaria uma maior autonomia para estabelecer uma agenda de investigação própria, com menos influência de pressões do Norte, e com uma maior aplicabilidade à região.

Todavia, é preciso não perder de vista o fato de que os países que estão agrupados sob o manto de "Países do Sul" ainda que compartilhem um passado histórico com algumas semelhanças, configuram-se como um grupo bastante heterogéneo pelas diferenças sócio-económicas, políticos e culturais, tanto no contexto local como regional. Portanto, o conceito de Cooperação Sul-Sul refere-se a uma categoria multidimensional, que transborda a categoria geográfica e assenta numa concepção política e económica não homogénea (Lechini, 2014).
Por conta dos acontecimentos políticos e económicos internacionais (consolidação da União Europeia, queda do muro de Berlim, crise económica nos países do Sul) , ao longo da década de 1980 e 1990, a CSS perdeu parte da sua força inicial. Todavia, nos dias atuais, uma vez mais, por consequência de inéditas conformações políticas e económicas resultantes de processos de relocalização do poder económico, a CSS vem restabelecendo a sua força e relevância. A melhoria da inserção internacional dos países periféricos por meio da integração regional é uma das principais apostas desta nova fase das Cooperações Sul-Sul (Creus, 2014; Velho, 2000).

\section{Cooperações Sul-Sul no campo científico: o caso do Mercosul}

As tentativas de cooperação entre os países da América do Sul são antigas. Uma das primeiras experiências da CSS entre o Brasil e a Argentina, ainda sob governos ditatoriais, foi o convénio de intercâmbio cultural assinado entre estes dois países, em 1968, retomado em 1980 em forma de acordo de cooperação em ciência e tecnologia. Diversos outros acordos firmados entre o Brasil e a Argentina podem ser apontados como exemplo de CSS: o Programa de Integración e Cooperación Económica (PICE) (1986), El Acta de Integración (1986), El tratado de integración, Cooperación y Desarrollo (1988), Acuerdo de Complementación Económica, no 14 (1990) e podem ser identificados como sementes do projeto do Mercado Común del Sur (Mercosul) que veio a concretizar-se posteriormente.

Em de Março 1991, em Assunção, Brasil, Argentina, Paraguai e Uruguai firmaram o tratado de Assunção, constituindo o Mercado Comum do Sul (Mercosul) o qual foi ratificado e entrou em vigor em 1994. O tratado, para além de organizar os países como um bloco comercial, tinha igualmente como objetivo superar obstáculos existentes no que diz respeito ao desenvolvimento de novas tecnologias, uma vez que o atraso tecnológico reforçava a dependência económica destes países em relação ao Norte Global.

Atualmente, o bloco do Mercosul é composto por Brasil, Argentina, Paraguai, Uruguai e Venezuela, enquanto a Bolívia está em processo de adesão e o Chile, Colômbia, Equador, Peru, Guiana e Suriname são Estados Associados (Corder et al., 2002; Velho, 2000). Segundo Krawczyk (2008), este tipo de aliança entre países, tal qual a União Europeia, é uma resposta aos efeitos da globalização económica neoliberal, constituindo-se como uma tentativa de oferecer aos estados novos instrumentos de poder e legitimação. Neste sentido, os países que compõem o Mercosul, unidos teriam mais poder para se colocaram diante das exigências do mercado internacional. 
Desde a sua criação, para além dos objetivos económicos, o Mercosul declara no seu discurso oficial que as atividades de cooperação no âmbito científico são uma das suas principais esferas de ação. Uma prova disso é que dentro de seu marco institucional, há um fórum específico de debate e coordenação das questões de ciência e tecnologia a Reunión Especializada en Ciencia y Tecnologia (RECYT), que busca identificar linhas de interesse conjunto aos países do bloco.

É interessante perceber que ainda que desde antes da criação do bloco, alguns países já experimentassem acordos de cooperações científicas (como caso do Brasil e da Argentina que desde a década de 1980 haviam estabelecido comissões conjuntas de desenvolvimento e integração de setores estratégicos, nomeadamente, aeronáutica e novas tecnologias) e que a cooperação científica seja um dos objetivos explícitos do Mercosul, as cooperações formais entre os países do bloco começaram a despontar efetivamente apenas nos últimos 15 anos. Trata-se, portanto, de uma cooperação bastante recente que só tomou força quando as instituições académicas e científica assumiram um novo posicionamento para se fortalecerem dentro do âmbito regional e obtiveram mais apoio dos governos nacionais (Marí et. al., 2001).

A restauração dos regimes democráticos aos países do Mercosul, na década de 1980, contribuiu de forma direta e fundamental para que fosse possível iniciar projetos de cooperação científica na região. Por um lado, o processo de democratização tanto permitiu a circulação de investigadores/as entre os países, como também possibilitou o regresso de muitos investigadores/as que haviam sido obrigados/as a deixar os países de origem por motivos de perseguição política (Krawczyk, 2008; Marí et al., 2001). E, por outro lado, uma parte daqueles/as que foram exilados/as durante o regime ditatorial optou por permanecer no país onde se encontrava, mas retomou contato com membros das suas instituições de origem através de colaborações em projetos e do incentivo ao intercâmbio de orientandos/as e orientadores/as de uma instituição para outra. Assim, foi possível dar os primeiros passos para a constituição de um corpo científico internacional qualificado capaz de fortalecer as atividades científicas regionais.

De acordo com Velho (2000), apesar dos esforços anteriores entre alguns países de estabelecerem cooperações científicas e de oficialmente o desenvolvimento de tecnologias e ciência ser uma pauta na agenda do Mercosul, na prática o que se vê é que as instituições, direta ou indiretamente ligadas às atividades de Ciência e Tecnologia - organismos governamentais, universidades, institutos de investigação ou empresas - não vêm a cooperação com os países do bloco como prioritária. Segundo a autora, os grandes projetos de investigação e as grandes redes de cooperação acontecem ainda, na sua maior parte, com países do Norte, sendo a cooperação regional no Mercosul vista como secundária e de importância relativa. Krawczyk (2008) afirma que claramente no caso do Brasil, o país ainda prioriza celebrar os seus convénios com os países do Norte nas área tecnológicas e mesmo nos projetos das áreas sociais opta-se por legitimar a tradição de cooperação com centros do Norte, reproduzindo a lógica da colonialidade do saber, apontada por Mignolo (2010). Embora, neste caso, seja preciso considerar também a existência de maiores financiamentos vindos do Norte, as lógicas das publicações e o grande número de acordos historicamente já firmados com os países do Norte. Neste sentido, deve-se refletir até que ponto não é a própria comunidade científica e académica do Sul que desvaloriza a sua própria produção científica e a criação e disseminação de conhecimento autóctone e localizado.

Marí (2001) ressalta que não há uma política clara direcionada para o fomento de cooperações e acordos intraregionais, sendo a maioria dos acordos entre centros e universidades do Mercosul resultantes do contato pessoal entre investigadores/as, cientistas e empresários/as em congressos, reuniões e encontros, sem contar com um suporte formal das instituições às quais pertencem. De acordo com Corder et al. (2002) as principais atividades de cooperação entre os países do Mercosul que se dão no âmbito institucional referem-se à padronização e à harmonização de normas técnicas e processos e à regulamentação de produtos e processos. Há, portanto, uma lacuna significativa no que diz respeitos a diretrizes formalizadas que contribuíam para o fortalecimento de laços científicos entre os países membros. A autora ainda afirma que no que diz respeito à cooperação entre empresas privadas dos diferentes países do bloco a tradição é o estabelecimento de relações quase que exclusivamente comerciais, não havendo, praticamente nenhuma preocupação com desenvolvimento de tecnologias ou transferência de conhecimentos ou competências. $E$, nos raros casos em que se detetam cooperações entre empresas com esses fins, elas são, via de regra, iniciativas individuais das próprias empresas envolvidas, ou seja, fora do marco institucional das políticas internacionais do Mercosul desenhadas para este fim.

Apesar das dificuldades elencadas acima, há uma série de indicadores que corroboram a ideia de que a cooperação científica entre os países do Mercosul tem forte potencial de desenvolvimento, e que, portanto, deve ser estimulada. De acordo com Marí et. al. (2001) nos últimos dez anos registou-se um intenso crescimento, com destaque fundamental para o Brasil e a Argentina. As iniciativas individuais entre investigadores/as, as redes formais e 
informais estabelecidas, os distintos e consolidados programas interregionais de formação de professores são alguns destes indicadores. De acordo com os autores, a cooperação científica entre os países do Mercosul é mais significativa do que se costuma reconhecer normalmente. No caso específico das ciências sociais, o crescimento na participação em congressos regionais e a criação de entidades científicas regionais como a Reunião de Antropologia do Mercosul (RAM), a Associação Latino Americana de Sociologia (ALAS) e Asociación Latinoamericana de Ciencia Política (ALACIP) atestam também a atual intensificação da cooperação mercosulina.

Mais além, Velho (2000) e Corder et. al. (2002) apontam uma característica relevante das cooperações entre os países do Mercosul, mais do que se concentrarem em áreas de conhecimento específicas, como física, geografia ou engenharia, as relações de cooperação estabelecem-se em torno de uma problemática comum de interesse para as atividades económicas e políticas dos diferentes países do bloco, como a crise hídrica, produção agropecuária ou agrícola. Este tipo de prática atesta que, apesar das dificuldades e da escassa frequência em que ocorrem, as cooperações entre os distintos países do Mercosul é um potencial a ser desenvolvido. Tanto, há espaços para o estabelecimento de diálogos relevantes para o bloco dentro de uma lógica da CSS, como por vezes problemáticas regionais procuram respostas concertadas entre os diferentes estados (i.e. bacias hidrográficas e o seu aproveitamento). Percebe-se, portanto, que há caminhos possíveis para ações conjuntas entre países membros do Mercosul para resolverem as suas questões regionais a partir do desenvolvimento de tecnologias próprias, sem ter que se subordinar aos países do Norte.

Para além disso, outra experiência de cooperação inovadora entre os membros do bloco que merece ser considerada é a Asociación de Universidades Grupo Montevideo (AUGM), uma rede de universidades públicas, autónomas da Argentina, Brasil, Bolívia, Chile, Paraguai e Uruguai. A AUGM foi fundada em 1991 com o objetivo de ser uma espaço comum, regional de cooperação científica, tecnológica, educativa e cultural. A associação procura contribuir para o fortalecimento e consolidação de uma massa crítica de recursos humanos de alto nível e para a interação de seus membros com a sociedade no seu conjunto, difundindo os avanços do conhecimento, através de programas de mobilidade e cooperação internacional. Ao longo dos anos, cada vez mais, a AUGM se tem fortalecido como uma instância de cooperação científica entre as instituições membros (AUGM, 2015).

Apesar do valor da experiência da AUGM, Krawczyk (2008) aponta o fato de que, tal qual na União Europeia, no Mercosul o processo de integração das universidades tem ocorrido de forma impositiva a partir das instâncias burocráticas, com ênfase, principalmente na padronização curricular e almejando a empregabilidade e a competitividade. Para a autora, mais do que um processo de integração com fins científicos, trata-se de um processo marcado pelo objetivo de desenvolvimento do mercado regional.

Igualmente cabe pontuar que apesar do rico potencial da colaboração dos países do Mercosul e da sua insipiência, dinâmicas de hierarquias já começam a estabelecer-se. Isto é, a cooperação científica não se dá de forma igualitária entre os distintos países do bloco. Por exemplo, devido à sua importância económica e demográfica, o Brasil tem centralizado uma parte significativa destes acordos, enquanto a Bolívia tem assumido um papel figurativo (Corder et al., 2002; Krawczyk, 2008).

De acordo com Krawczyk (2008), é importante ressaltar que desde 2001, ainda que de forma embrionária, o Brasil vem direcionando as suas políticas de cooperação científica e tecnológica num marco de abertura a novos mercados e de liderança regional. Neste sentido, o país passou a incentivar, de forma mais forte, programas institucionais de cooperação Sul-Sul nos quais pudesse instituir a sua liderança, ao invés de investir apenas em parceiros mais tradicionais, como França, Alemanha e Estados Unidos. Contudo, nesses "novos" programas de cooperação o Brasil tem-se posicionado de forma hierárquica, reproduzindo tal qual os seus parceiros tradicionais, assimetrias e desigualdades.

Dentre o conjunto das políticas de cooperação internacional, citadas acima, o Brasil vem incentivando principalmente os projetos bilaterais que promovem o fortalecimento de vínculos institucionais entre países da região, seja através de programas bilaterais que financiam projetos conjuntos de pesquisa, de parcerias universitárias e /ou de formação de recursos humanos locais (Krawczyk, 2008: 47).

Por fim, o aumento e intensificação das relações do Brasil com outros países do Sul pode ser o resultado da maior visibilidade dada pelas agências de fomento a este tipo de programa por conta de uma melhor sistematização e organização de ações que já estavam em curso (Morosini, 2011) e de uma política de alargamento e diversificação das parcerias internacionais no seu todo, nas quais a América Latina e outras regiões do Sul, África de Língua Portuguesa sobretudo, resultam atrativas.

\section{Cooperações dentro do Mercosul: Brasil e Argentina}

Em relação aos países membros do Mercosul, a cooperação entre Brasil e Argentina é uma das mais consolidada. O Instituto de Pesquisas Espaciais (INEP), o Instituto de Pesquisas Energéticas e Nucleares (IPEN), o Centro Técnico de Aeronáutica (CTA) e o Centro Argentino Brasileiro de Biotec- 
nologia (CABBIO) são alguns exemplos de centros de investigação criados a partir de cooperações internacionais. Ainda no Centro de Energia Nuclear na Agricultura (CENA) e no Laboratório Nacional de Luz Síncontrón desenvolvem-se alguns projetos em parceira entre instituições dos dois países. Via de regra, o intercâmbio dá-se através de distintas atividades: visitas a universidades, laboratórios, participação em cursos, seminários, reuniões técnico-científicas e desenvolvimento de experiências conjuntas, resultando num número significativo de publicações em comum. Reforça-se assim a ideia de que existe um potencial de atuação entre os dois países a ser aproveitado e que, consequentemente, pode ser alargado pelos demais países do bloco (Coder et. al., 2002: 19).

Entre alguns motivos que justificam a cooperação entre Brasil e Argentina elenca-se a proximidade geográfica, o fato de os dois países terem sido colónias de países da península Ibérica (Portugal e Espanha) que partilhavam uma lógica de dominação semelhante e geraram economias fracas semiperiféricas, ambos os países aplicaram políticas de substituição de exportações e viveram processos e anos de ditadura semelhantes, que resultaram numa configuração económica, política e social relativamente similar, embora com algumas diferenças. Já dentre os obstáculos para a cooperação pode-se destacar a falta de fundos e de incentivo dos Governos dos dois países, a burocracia excessiva que envolve os poucos instrumentos de políticas de cooperação existentes (Marí, 2001) assim como também uma rivalidade histórica.

Os principais campos de cooperação entre os dois países consolidam-se nas áreas estratégicas nuclear e espacial, agropecuária, biotecnologia e projetos de parceira Universitária. Um dos programas mais relevantes chama-se "Programa de Centros Associados de Pós-Graduação Brasil e Argentina" assinado entre a Coordenação de Aperfeiçoamento de Pessoal de Nível Superior (CAPES) e a Secretaria de Políticas Universitárias da Argentina (SUP) em 2000 , no umbral da crise argentina de 2001/2.

\section{Metodologia}

Na definição dos objetivos deste estudo exploratório, tal qual Mari et. al. (2001) adotamos o conceito de cooperação científica alargada com base no Manual Frascati (OCDE, 2013) sob a rubrica do conjunto de práticas científica e tecnológicas, que incluem atividades de pesquisa e desenvolvimento, educação e formação científica e tecnológicas, serviços científicos e técnicos e as cooperações académicas entre Universidades.

E ainda que só seja possível retirar algumas reflexões iniciais, consideramos que os documentos analisados constituem-se como uma importante fonte de dados secundários que oferecem um material empírico relevante de ser analisado, embora exija ser enriquecido com informações de protagonistas (quer dos acordos como na sua implementação) num projeto posterior.

Por fim, esclarece-se que o objetivo deste artigo não é o de avaliar os programas de cooperação entre Brasil e Argentina, mas sim de refletir e discutir sobre as modalidades de cooperação existente entre os dois países e o potencial desta cooperação.

Resultados da análise

O Consejo Nacional de Investigaciones Científicas y Técnicas (CONICET), Argentina, o Conselho Nacional de Desenvolvimento Científico e Tecnológico (CNPq) e a Coordenação de Aperfeiçoamento de Pessoal de Nível Superior (CAPES), Brasil, figuram como algumas das principais agências de fomento de investigação científica e académica da Argentina e do Brasil, respetivamente.

A Argentina montou o seu o sistema de pós- graduação e investigação em etapas. O CONICET foi criado em 05 de fevereiro de 1958 com o propósito de ser um organismo académico promotor da investigação científica e tecnológica no país, portanto, um centralizador dos mecanismos de apoio à pesquisa universitária (Klein \& Sampaio, 1994). Atualmente, o Conselho integra investigadores/as de todas as áreas disciplinares, promove investigação e desenvolvimento científico e tecnológico em toda Argentina. De entre seus principais objetivos procura fomentar a investigação, almejando o avanço científico e tecnológico, o desenvolvimento da economia e a melhoria da qualidade de vida no país; incentivar o intercâmbio e a cooperação científica dentro do país e no estrangeiro; organizar e financiar institutos, laboratórios e centros de investigação que funcionem em Universidades ou Instituições privadas (CONICET, 2015). É importante ressaltar também que desde 1961 o CONICET já abrigava uma carreira profissional de investigação em ciência e tecnologia, que foi sendo reformulada ao longo dos anos, para os/as investigadores/as associados ao Conselho e outros/as afiliados/as a Universidades.

No Brasil, por sua vez, o sistema de pós-graduação e investigação, desde o início, baseou-se no pluralismo institucional e na especialização funcional, o CNPq e a CAPES tinham funções e áreas de atuação definidas e diferenciadas. Esta diferenciação e descentralização foi reforçada pelo surgimento de fundações estaduais de apoio à pesquisa, como a FAPESP ou a FAPERJ (Klein \& Sampaio, 1994). Ao contrário do CONICET, nem o CNPq, nem a CAPES, nem as fundações estaduais de apoio à pesquisa possuem carreira profissional de pesquisadores. O vínculo com essas instituições dá-se através de bolsas de pesquisas concedidas a 
membros de grupos de pesquisa das Universidades formalmente recenseadas.

O CNPq foi criado em 1951 e tem como objetivo principal a pesquisa científica e tecnológica e o incentivo à formação de pesquisadores/as brasileiros/as. Ao longo dos anos tem desempenhado um papel fundamental na formulação, implementação e condução das políticas de ciência, tecnologia e inovação, buscando contribuir para "o avanço das fronteiras do conhecimento, o desenvolvimento sustentável e a soberania nacional". É da sua responsabilidade também fomentar o desenvolvimento e a manutenção da pesquisa científica e tecnológica no país, promover a realização de acordos, protocolos, convénios, programas de intercâmbio e transferência de tecnologia, entre entidades públicas e privadas, nacionais e internacionais (CNPq, 2015).

Já a Coordenação de Aperfeiçoamento de Pessoal de Nível Superior (CAPES), primeiramente, Campanha Nacional de Aperfeiçoamento de Pessoal de Nível Superior, criada em 11 de Julho de 1951 tinha o objetivo de "assegurar a existência de pessoal especializado em quantidade e qualidade suficientes para atender às necessidades dos empreendimentos públicos e privados que visam ao desenvolvimento do país". Nos dias de hoje, fundamentalmente, ocupa-se da expansão e consolidação da pós-graduação stricto-sensu de todo os país e entre suas linhas de ação pode-se destacar o acesso e a divulgação da produção científica e promoção da cooperação internacional (CAPES, 2015).

A criação das agências de fomento em questão deu-se no final da Segunda Guerra Mundial e pode ser associada a duas razões: por um lado as transformações que acontecem nos vínculos políticos e económicos entre os países da Europa e da América do Sul resultantes da conjuntura do pós guerra e por outro as recomendações defendidas pela Comissão Económica para a América Latina e o Caribe (CEPAL) para a aplicação do modelo se substituição de importações, ou seja um novo modelo de desenvolvimento económico alicerçado no setor industrial e com critérios seletivos para a importação. Essas duas interpretações podem ser entendidas de maneira complementar, ambas apontam para o entendimento de que as agências de fomento em questão tinham um objetivo muito claro, formar recursos qualificados capazes de acompanhar a expansão dos processes de industrialização, atendendo às exigências do mercado. Nesta lógica, as carreiras tidas como prioritárias eram aquelas diretamente relacionadas com a modernização da economia e do setor industrial, tais como as engenharias, a física e a matemática (Cruz, 2012). Passados mais de meio século da criação destas agências, a ênfase na formação de recursos qualificados para o mercado imediato parece não se ter alterado muito.
Sobre o CONICET Hurtado e Feld (2008) afirmam que a história da instituição está marcada por uma trajetória muito instável, que sofreu bastante com as oscilações políticas e económicas do país, resultado, sobretudo, dos governos civis e militares que se alternaram desde a sua criação. O mesmo se pode dizer em relação ao CAPES e ao CNPq, igualmente, atravessados pelas profundas transformações políticas e económicas desde a sua criação até aos nossos dias. As descontinuidades das políticas de desenvolvimento, ciência e investigação, durante os governos militares e os profundos cortes orçamentais feitos na década de 80 , consequência das crises económicas que se alastravam com força pela América Latina, somado à perda de investigadores/ as e cientistas com altos níveis de qualificação resultante das perseguições políticas, estagnaram o crescimento das agências e consequentemente das suas ações.

Durante o regime ditatorial, a saída de intelectuais da América do Sul para centros do Norte por conta de perseguições políticas deixou marcas profundas no desenvolvimento científico na região. A fuga de cérebros entre os anos 1960 e 1980 enfraqueceu a produção intelectual e tecnológica e, consequentemente, a economia da região. Devido à repressão e censura ideológica, a ausência de políticas e programas científicos consolidados, a instabilidade das instituições e a intensificação das políticas de atração de cientistas e académicos, empreendidas pelos países do Norte, uma parte significativa da massa crítica da América do Sul viu-se obrigada a deixar o seu país. Esse marcado êxodo científico no sentido Sul-Norte reforçou as desigualdades entre as duas regiões, uma vez que contribuiu para a concentração de conhecimentos nos centros do Norte (Oteiza, 1965; Pellegrino, 2001).

Atualmente, uma resposta empreendida por alguns países do Sul para tentar redimir as consequências negativas resultantes da fuga de cérebros, tanto por perseguições políticas como por desinvestimento científico, tem sido a repatriação ou reincorporação de cientistas que se encontram no estrangeiro através de programas específicos. No caso argentino, o programa RAICES ou Red de Argentinos Investigadores y Científicos en el Exterior (Padilla e Ortiz, 2014) já repatriou mais de mil investigadores.

Contudo, apesar dos altos e baixos sofridos é inegável o reconhecimento da importância que estas agências tiveram no desenvolvimento da ciência, da tecnologia e da investigação em ambos países. Principalmente no que diz respeito a cooperação internacional através de projetos de investigação em colaboração com outras instituições internacionais. Durante um período em que tanto na Argentina como no Brasil os títulos de mestrados e doutoramentos ainda não eram pré-requisitos obrigatórios para a 
construção de uma carreira académica, bem como o nível do ensino e da investigação era pautado por outras variáveis, as agências de fomento tiveram um papel importante no que diz respeito ao financiamento para a qualificação no exterior dos seus/ /suas investigadores/as (Morosini, 2011). a isso a variada e extensa linguagem que as ciências humanas dispõem ao analisar um fenómeno que acaba por prejudicar a colaboração entre diferentes escolas de pensamento. Igualmente, é preciso ter em consideração que a especialização do conhecimento acerca dos fenómenos sociais também está

Figura $1 \triangleright$ Antecedentes de cooperação CONICET-CNPq ${ }^{1}$

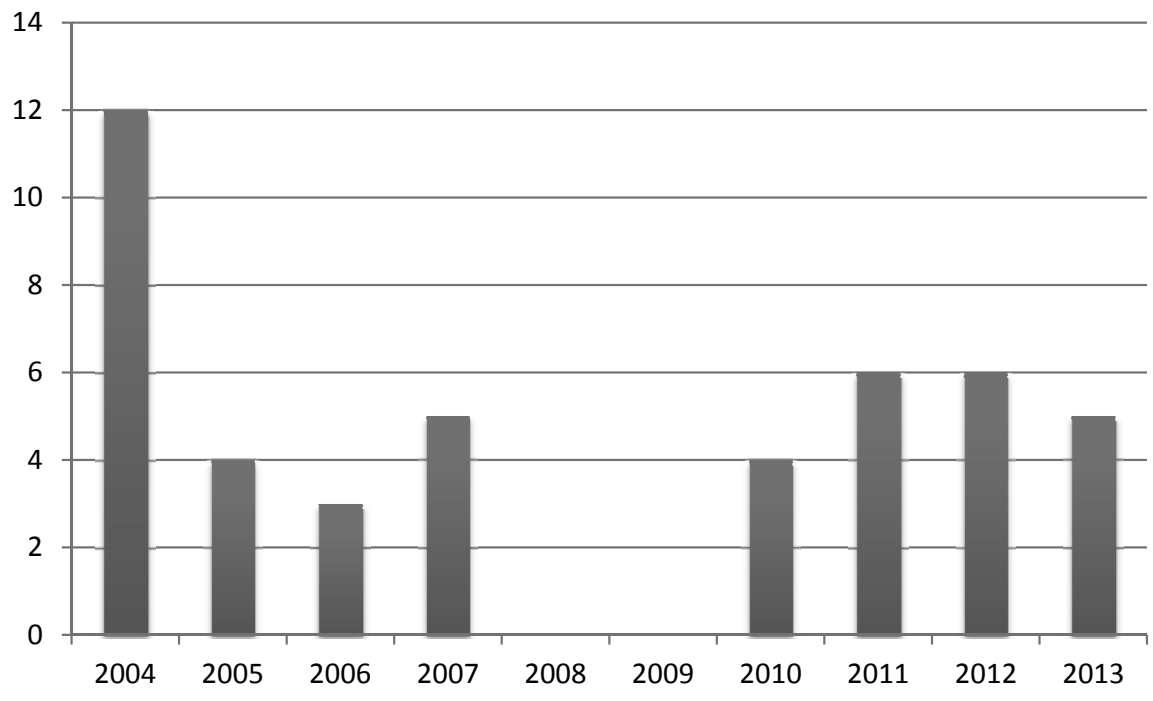

Fonte: CONICET, 2015

De acordo com dados fornecidos pelo CONICET (2015) ao longo dos anos de 2004 e 2013, apesar da variação no número de projetos de cooperação científica entre o CONICET e o CNPq (Figura 1), as áreas prioritárias eram as de: tecnologias de informação e comunicação, ciências agropecuárias, tecnologias limpas, recursos renováveis e não renováveis, risco e vulnerabilidade social diante de eventos naturais e ambientais.

O fato de que estes convénios se consolidam primordialmente no âmbito das ciências naturais e das tecnologias, fornece algumas pistas para refletir acerca da influência da lógica neoliberal e das hierarquias epistémicas na produção científica. Por um lado, os projetos nestas áreas são financiados segundo os interesses comerciais e estratégicos comuns aos dois países, deixando de lado as indagações e curiosidades científicas relacionadas ao conhecimento puro às aspirações morais e culturais e acumulação de experiências intelectuais, sobrevalorizando o conhecimento técnico e aplicado aproximando-se daquilo de Krawczyk (2008) denomina capitalismo científico. Por outro lado, os ditos "problemas de foro social" podem ser lidos desde distintas perspetivas com justificativas variadas dificultando uma definição comum do "problema" e, consequentemente, a planificação de uma intervenção conjunta. Soma-se atravessada por lógicas territoriais e nacionalistas que, não raramente, não dialogam em entre si uma vez que partem de pressupostos de análise e de intervenção distintos baseados nas conjunturas económicas, políticas e sociais locais, dificultando ainda mais as ações de cooperação internacionais.

\section{Considerações finais}

O crescimento dos acordos de cooperação científica internacional, incluindo aqueles de caráter CSS, pode ser entendido como uma tendência resultante dos processos de globalização, enquadrando-se nas práticas de internacionalização da ciência em seus diferentes níveis: investigação, ensino e transferência de tecnologia. Países, regiões e blocos de integração (i.e. Mercusul, UE) podem beneficiar-se de formas diferenciadas destes tipos de acordos, aplicando estratégias alternativas aos modelos de cooperação mais tradicionais que promovem o crescimento económico e desenvolvimento social a partir do avanço da ciência. Neste sentido, a cooperação científica, especialmente dentro da lógica da CSS, é percebida como uma organização horizontalizada, permitindo a construção de uma ciência e de um conhecimento científico que respondam melhor às necessidades locais e que surgem de 
interesses comuns ou complementares em áreas afins. Ademais, ainda que a CSS deva ser analisada com cautela, ela pode, igualmente, ser considerada uma ferramenta estratégica para a consolidação de blocos de cooperação e fortalecimento dos sistemas científicos dos Estados envolvidos.

Os casos de cooperação científica entre Brasil e Argentina ilustram um exemplo relativamente bem sucedido de CSS. Ao longo dos anos, apesar das dificuldades económicas e políticas que os dois países atravessaram, diversos esforços têm sido empreendidos no sentido de fortalecer atividades de investigação e docência envolvendo instituições brasileiras e argentinas. Embora nem todas as parcerias tenham atingido os resultados esperados, é inegável reconhecer os benefícios que trouxeram para ambos os países e para o desenvolvimento regional.

Historicamente, Brasil e Argentina competiram pelo protagonismo político e económico na América do Sul, os acordos de cooperação científica têm promovido uma maior integração entre os dois países em áreas estratégicas para o contexto local e regional, ao mesmo tempo que, apesar de incipiente, têm permitido uma maior autonomia das suas instituições em relação àquelas dos países do Norte.

Contudo, a despeito de se mostrar como uma alternativa viável e benéfica para os dois países é importante questionar até que ponto estes acordos de cooperação científica promovem realmente uma política de formação e produção de uma ciência regional, capaz de mobilizar compromissos e alianças regionais sólidas que provoquem um impacto significativo no desenvolvimento científico, tecnológico e das políticas públicas e que contribuam para a independência da região em relação aos conhecimentos e tecnologias vindas do Norte. Ou, se na prática, não passam de ações individualizadas de cada centro que aparecem montadas como peças de um quebra cabeças em artigos internacionais, relatórios ou em apresentações em eventos.

\section{Notas}

1 Nos anos de 2008 e 2009 nenhum novo convénio foi firmado entre as duas agências.

\section{Referências bibliográficas}

AUGM, L. A. de U. G. M. (2015), Institucional | Grupo Montevideo. Retrieved from http://grupomontevideo.org/sitio/institucional/ Acessado em: 06/07/2015

CAPES, C. de A. de P. de N. S. (2015), Coordenação de Aperfeiçoamento de Pessoal de Nível Superior. Retrieved from http://www.capes.gov.br Acessado em: 06/07/2015.

CNPq, C. N. de D. C. e T. (2015), Conselho Nacional de Desenvolvimento Científico e Tecnológico.
Retrieved from http://www.cnpq.br/ Acessado em: 20/05/2015.

CONICET, C. N. de I. C. y T. (2015), CONICET - Consejo Nacional de Investigaciones Científicas y Técnicas. Retrieved from http://www.conicet.gov.ar/ Acessado em: 16/05/2015.

COMISSÃO ECONÔMICA PARA A AMÉRICA LATINA E O CARIBE (CEPAL). http://www.cepal.org/pses33/ noticias/paginas/1/38821/2010-166-SES-3311_ Cooperacion_internacional_en_el_nuevo_contexto_mundial.pdf_Acessado em: 13/12/2015.

CORDER, S., Costa, M., Gomes, E., \& Velho, P. (2002), Mercosur: cooperación en ciencia y tecnología, Nueva Antropologia, XVIII, pp. 9-30.

CREUS, N. (2014), Una historia de idas y vueltas: los dilemas de la cooperación entre Argentina y Brasil, in G. Lechini (Ed.), La cooperación sur-sur en las políticas exteriores de Argentina y Brasil en el siglo XXI, Rosario, UNR, pp. 61-73.

CRUZ, R. (2012), Se a CAPES somos nós, quem somos nós? A pós-graduação brasileira em busca de uma identidade. Retrieved from http://www. geografia.fflch.usp.br/graduacao/apoio/Apoio/ Apoio_Gloria/2012/1s/ATT109.pdf Acessado em: $13 / 12 / 2015$.

DEDJIER, S. (1971), Primeras migraciones, in El drenaje de talentos, Buenos Aires, Paidós.

DOMINGUES, A., \& Costa, M. da C. (2013), As políticas públicas de cooperação internacional em C\&T: uma análise particular. Teoria\&pesquisa - Revista de Ciência Política, 22 (1), pp. 91-101.

HURTADO, D., \& Feld, A. (2008), Los avatares de la ciencia, Nómada, 12, pp. 3-7.

KIM, T. (2009), Shifting patterns of transnational academic mobility: a comparative and historical approach, Comparative Education, 45 (3), pp. 387-403.

KLEIN, L., \& Sampaio, H. (1994), Políticas de ensino superior na América Latina - uma análise comparada, Revista Brasileira de Ciências Sociais, 24, pp. 85-109.

KRAWCZYK, N. (2008), As Políticas de Internacionalização das Universidades no Brasil: o caso da regionalização no Mercosul1, Jornal de Políticas Educaionais, 4, pp. 41-52.

LECHINI, G. (2014), La cooperación sur-sur en las políticas exteriores de Argentina y Brasil en el siglo XXI, Rosario, UNR.

MARÍ, M., Estebanez, M. E., \& Suárez, D. (2001), La cooperación en ciencia y tecnologia de Argentina con los países del Mercosur, Redes, 8 (17), pp. 59-82.

MIGNOLO, W. (2003a), Globalization and geopolitics of knowledge: the role of the humanities in the corporate universit, Neplanta: Views from Sotuh, 4 (1), pp. 97-119.

MIGNOLO, W. (2003b), Os esplendores e as misérias da "ciência": colonialidade, geopolítica do conhecimento e pluri-versalidade espistémica, in B. Santos (Ed.), Conhecimento prudente 
para uma vida decente: "Um discurso sobre as ciências" revisitado ( $631^{\text {st }}-672^{\text {nd }}$ ed.), Porto, Afrontamento.

MIGNOLO, W. (2010), Epistemic Disobedience, Independent Thought and Decolonial Freedom, Theory, Culture \& Society, 26 (7-8), pp. 159-181.

MOROSINI, M. C. (2011), Internacionalização na produção de conhecimento em IES Brasileiras: cooperação internacional tradicional e cooperação internacional horizontal, Educação Em Revista, 27 (1), pp. 93-112.

OCDE, O. de C. e D. E. (2013), Manual de Frascati 2002 Mediação de atividades cientíticas e tecnológicas Tipo de metodologia proposta para levantamentos sobre pesquisa e desenvolvimento experimental, Paris, França.

OTEIZA, E. (1965), La emigración de ingenieros argentinos dentro del contexto de las migraciones internacionales: un caso de brain drain latinoamericano, Revista Internacional Del Trabajo, $72(6)$.

PADILLA, Beatriz and Ortiz, Alejandra (2014), "Transnational Citizenship: Latin Americans, in Portugal / Ciudadanía transnacional: latinoamericanos en Portugal", Revista CIDOB d'Afers Internacionals, No 106/107, pp. 30-59.

PELLEGRINO, A. (2001), Drenaje, movilidad, circulación: nuevas modalidades de la migración cualificada, Nota de Población, (73), pp. 129-162.
REMOTTI, L., Damvakeraki, T., Ploder, M., \& Sterner C. (2014), International Science and Technology Cooperation in the EU's $7^{\text {th }}$ Framework Programme: the specific programme "Cooperation" and its thematic areas, Bruxelas, European Comission.

VANZ, S. A. de S., \& Stumpf, I. R. C. (2010), Colaboração científica: revisão teórico conceitual, Perspectivas Em Ciência Da Informação, 15 (2), pp. 42-55.

REUNIÃO ESPECIALIZADA EM CIÊNCIA E TECNOLOGIA DO MERCOSUL (RECYT) (2015), Programa Quadro de Ciência, Tecnologia e Inovação do Mercosul (2015-2019). http://www.recyt.mincyt.gov.ar/ files/ProgramaMarco/Programa_Marco_CTI_201519.pdf Acessado em: 06/12/2015.

SECRETARÍA GENERAL IBEROAMERICANA (SEGIB) (2008), "Segundo informe de la cooperación SurSur en Iberoamérica", Estudios SEGIB, No 3. [en línea]. http://www.segib.org/documentos/esp/ sur_sur_web_ES.PDF. Acessado em: 06/12/2015.

VELHO, L. (2000), Redes regionales de cooperación en CYT y el mercosur, Redes, 15 (7), pp. 112-130.

XALMA, C. (2012), Report on South-South Cooperation in Ibero-America 2012, Madrid, Secretaría General Iberoamericana.

XALMA, Cristina (2013), "Generando Indicadores para la Cooperación Sur-Sur, Una mirada al trabajo realizado desde el Programa Iberoamericano para el Fortalecimiento de la Cooperación Sur-Sur", Documento de trabajo No 4.

Recebido a 05/10/2015. Aceite para publicação a 05/12/2015.

Thais França (thaisfrancas@gmail.com). Universidade do Minho, Centro Interdisciplinar de Ciências Sociais, CICS. NOVA (Polo UMinho). Campus de Gualtar, 4710-057 Braga, Portugal.

Beatriz Padilla (padilla.beatriz@gmail.com). Instituto Universitário de Lisboa (ISCTE-IUL), Centro de Investigação e Estudos de Sociologia (CIES-IUL) \& Universidade Nova de Lisboa, Centro Interdisciplinar de Ciências Sociais (CICS.NOVA). CIES-IUL, Ed. ISCTE, Avenida das Forças Armadas, 1649-026 Lisboa, Portugal. 